\title{
AVALIAÇÃO ESTRUTURAL DA SUBESTAÇÃO DE ENERGIA DA UFES APÓS INCÊNDIO
}

\author{
BREMENKAMP, CINNDHY \\ Graduanda em Engenharia Civil \\ Universidade Federal do Espírito Santo \\ Espírito Santo; Brasil \\ cinndhyuab@gmail.com
}

\author{
MOTA, GABRIELA \\ Graduanda em Engenharia Civil \\ Universidade Federal do Espírito Santo \\ Espírito Santo; Brasil \\ gabrielasdamota@gmail.com
}

\author{
MARTINELLI, LETÍCIA \\ Graduanda em Engenharia Civil \\ Universidade Federal do Espírito Santo \\ Estado; País \\ leticiacarvalhomartinelli@gmail.com
}

\author{
SOUZA, RODRIGO \\ Graduando em Engenharia Civil \\ Universidade Federal do Espírito Santo \\ Espírito Santo; Brasil \\ rodrigoodesouzaa@gmail.com
}

\author{
VIEIRA, GEILMA \\ Doutora em Engenharia Civil \\ Universidade Federal do Espírito Santo \\ Espírito Santo; Brasil \\ geilma.vieira@gmail.com
}

\section{RESUMO}

As estruturas de concreto são bastante resistentes ao fogo pela baixa condutividade térmica e a natureza não combustível do material, funcionando até certo ponto como uma barreira que previne a propagação do calor. Entretanto, quando o concreto é submetido a altas temperaturas por longo tempo, pode haver uma deterioração das propriedades mecânicas, levando a uma redução da rigidez da estrutura. Quando ocorre um incêndio numa edificação, a preocupação principal é a garantia de que a estabilidade da mesma esteja preservada. Deste modo, visando avaliar as condições estruturais da Subestação de energia da Universidade Federal do Espírito Santo após ocorrência de um incêndio, o trabalho apresenta os procedimentos realizados para análise das manifestações patológicas surgidas no local, com base nas resoluções de Lichtenstein. Os resultados apontam que as propriedades mecânicas da estrutura foram alteradas com a ação dos produtos do incêndio, afetando assim, a integridade da estrutura de concreto armado.

Palavras-chave: incêndio, concreto armado, danos estruturais, subestação elétrica da UFES.

\section{ABSTRACT}

The concrete structures are quite fire resistant due to the low thermal conductivity and the non-combustible nature of the material, functioning to a certain extent as a barrier preventing the propagation of heat. However, when the concrete is subjected to high temperatures for a long time, there may be a deterioration of the mechanical properties, leading to a reduction of the rigidity of the structure. When a fire occurs in a building the main concern is the guarantee that the stability of the same is preserved. Therefore, in order to evaluate the structural conditions of the university substation as a result of a fire, the work presents the procedures performed in the analysis of the pathological manifestations that appeared in the place, based on the definitions of Lichtenstein. The results indicate that the mechanical properties of the structure were altered by the action of fire products, thus affecting the integrity of the reinforced concrete structure.

Keywords: Fire, reinforced concrete structure, structural damage, energy substation of UFES.

\section{INTRODUÇÃO}

Embora o uso do aço na construção civil tenha crescido muito nos últimos 15 anos (CBCA, 2015) no país, o sistema construtivo estrutural mais utilizado ainda é o concreto armado. Esse fato pode ser explicado pelo conservadorismo por parte das empresas e profissionais da área e pelo amplo conhecimento técnico acumulado ao longo dos anos na execução desse tipo de sistema. Além disso, a alta resistência à compressão e durabilidade do concreto, aliada à alta resistência à tração e ductilidade do aço, configuram uma estrutura de ótimo desempenho para o ramo da construção. 
Entretanto, em situações de elevadas temperaturas, essas propriedades são modificadas devido às alterações na intensidade das forças de ligação interatômicas na microestrutura (COSTA, 2002).

Diante das diversas ocorrências de incêndios no Brasil, houve a necessidade de implementar mudanças no sistema brasileiro de prevenção e combate ao incêndio, para que possam ser evitados sinistros como o ocorrido no prédio da subestação de energia da Universidade Federal do Espírito Santo, em maio de 2019. De acordo com a reitoria da universidade, o incêndio foi devido a uma falha na rede elétrica do Campus.

A estrutura do edifício atingido é constituída por concreto armado e o sistema de vedação por blocos cerâmicos. Além disso, possui apenas um pavimento, composto por uma sala de quadros, uma sala de baterias e dois compartimentos, com um transformador em cada. $\mathrm{O}$ incêndio atingiu apenas um dos compartimentos, mas teve impacto em toda a alvenaria $\mathrm{e}$ estrutura adjacente.

Para fins didáticos, denominou-se "Compartimento 1" o cubículo atingido diretamente pelo fogo e "Compartimento 2" o cubículo que não foi alcançado pelas chamas.

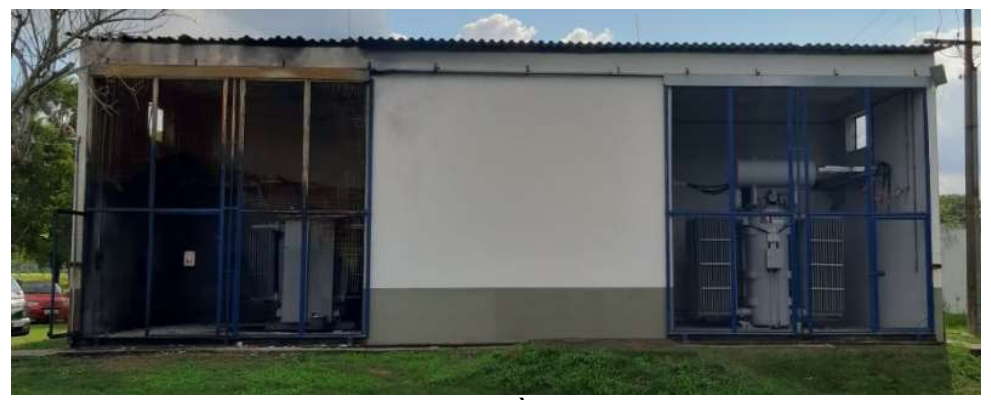

Figura 1: Situação pós incêndio do prédio da subestação. À esquerda, compartimento 1, afetado pelo incêndio. À direita, compartimento 2.

Fonte: Autores (2019).

A Figura 2 mostra a planta baixa da estrutura, na qual foram realizados os ensaios destrutivos e não-destrutivos descritos em Procedimentos Metodológicos deste trabalho. Os elementos afetados foram os pilares P8, P9, P12 e P13 e as vigas V3, V4, V5 e V6.

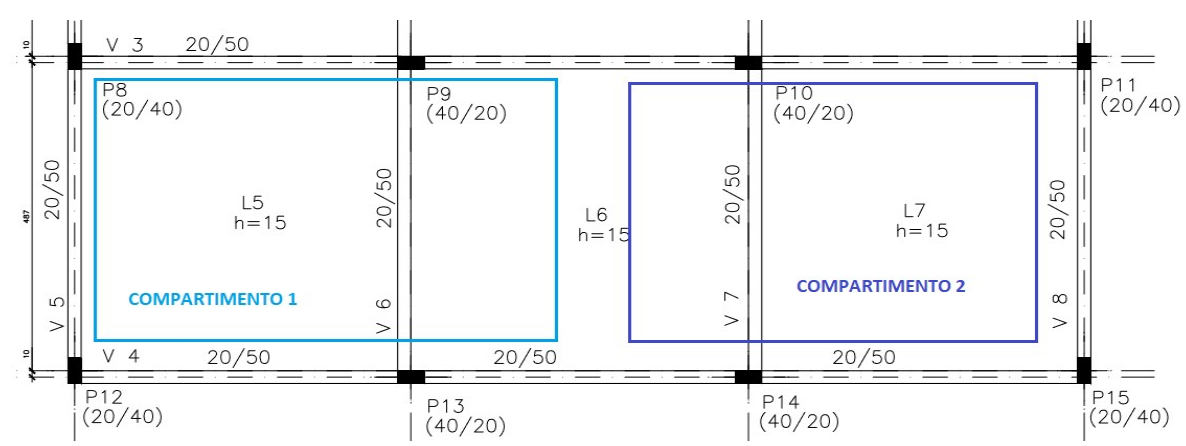

Figura 2: Planta estrutural de cobertura com indicação dos compartimentos.

Fonte: Projeto estrutural da subestação (2007).

\subsection{Objetivo}

O trabalho tem o intuito de diagnosticar o comportamento físico e mecânico da estrutura de concreto armado, após o incêndio ocorrido no edifício da subestação de energia da Universidade Federal do Espírito Santo. Por meio de ensaios normalizados, a estrutura será avaliada com relação à sua resistência mecânica, aspecto superficial, integridade interna, condições de alcalinidade do concreto e corrosão das armaduras. 


\subsection{Revisão bibliográfica}

Segundo Costa e Silva (2002), durante a ocorrência de um incêndio, o aumento da temperatura em elementos estruturais decorrente da ação térmica, provoca alterações na micro e na macroestrutura do concreto armado, refletindo em uma diminuição progressiva da sua capacidade portante. Em alguns casos, no decorrer do processo de queima, o esforço solicitante em uma seção pode se igualar ao esforço resistente, resultando em colapso.

O concreto é composto por partículas de agregados dispersos em uma matriz de cimento e que se comporta como um material único à temperatura ambiente. Contudo, quando submetido a altas temperaturas, seus constituintes reagem de forma diferente devido a heterogeneidade. Enquanto o agregado apresenta expansão volumétrica até desestruturar-se quimicamente, a pasta de cimento se contrai (SILVA, 2001), gerando assim tensões térmicas na interface do agregado graúdo devido a incompatibilidade térmica.

Essas deformações diferenciais entre os componentes, aliadas às altas pressões internas de vapor d'água, conduzem para a desagregação do concreto, resultando em delaminação, fissuração excessiva e desplacamento das camadas superficiais, fenômeno denominado de lascamento. O desprendimento do cobrimento da armadura devido ao lascamento compromete o desempenho estrutural, pois expõem as armaduras ao calor excessivo durante o incêndio. Uma vez expostos, o aço experimenta efeitos de fluência e de dilatação excessiva, além da redução da aderência entre as barras e o concreto.

Segundo Kalifa et al. (2000), a desestruturação química da pasta de cimento se inicia a partir dos $200^{\circ} \mathrm{C}$, quando as fissuras superficiais se tornam visíveis devido à retração por perda de água. Já acima dos $400^{\circ} \mathrm{C}$, Neville (1997) descreve queda acentuada da resistência devido a ocorrência de uma série de reações físico-químicas, onde a água evaporada reduz as forças de Van der Walls entre as camadas de silicato de cálcio hidratado (C-S-H), composto que responde pela alta resistência à compressão do material.

Em situações com elevado gradiente de temperatura, a evaporação da água adsorvida e livre na massa cimentícia decompõem os produtos hidratados que constituem o concreto, como o aluminato de cálcio, a etringita e o hidróxido de cálcio. Como o $\mathrm{Ca}(\mathrm{OH}) 2$ é o responsável pela alta alcalinidade do material, possui, portanto, capacidade de apassivar a armadura por impedir oxidação posterior (CASCUDO, 1997).

Nessas condições, os gases agressivos liberados na combustão dos materiais sob ação do fogo, propiciam que agentes como o gás carbônico $\left(\mathrm{CO}_{2}\right)$ penetrem no concreto por ação convectiva, e interagem com os componentes alcalinos presentes na massa, formando assim, carbonato de cálcio que expande da superfície, para o interior do material. Essa interação provoca uma diminuição do $\mathrm{pH}$, e consequentemente, eleva o risco de corrosão da armadura, devido à perda da funcionalidade protetora da película apassivadora sobre o aço.

O tempo necessário para que a frente de carbonatação avance no concreto, desde a superfície até atingir a armadura, é função da espessura do concreto de cobrimento e do coeficiente de difusão do CO2 nesse concreto (BENTUR et al., 1997 apud RIBEIRO, 2009), fatores que sofrem alterações quando submetidos à ação do fogo.

De acordo com a norma NBR 15200 (ABNT, 2012), a estrutura só pode ser reutilizada após um incêndio depois de realizada a vistoria, avaliada a capacidade remanescente e verificada a necessidade de recuperação das características que a mesma apresentava antes do incêndio. É necessária, portanto, levantamento de subsídios conforme a metodologia proposta por Lichtenstein (1986), composta por inspeção visual do local, coleta de informações por anamnese, realização de ensaios normatizados e também de pesquisas pertinentes ao tema, que permitem assim, uma análise das características físicas e químicas da estrutura afetada.

Normalmente, após o resfriamento, o concreto não recupera a resistência inicial, sendo o valor final função da temperatura máxima atingida, do tempo de exposição, do traço do concreto e da velocidade de resfriamento. Deste modo, diante do diagnóstico obtido é possível desenvolver intervenções corretivas e preventivas, evitando assim, o alastramento de manifestações patológicas tão prejudiciais a vida útil da edificação.

Para restabelecer o desempenho mecânico, é necessário tratamento, reforço ou até mesmo demolição da edificação (SANTIAGO, 2011). Em alguns casos, pode ser aplicado, a técnica de realcalinização que consiste em reposição de nata de cimento com adições minerais como metacaulim, sílica ativa e cinzas volantes, por meio de injeções ao ar comprimido dentro da área comprometida. Essa e outras condutas adotadas a partir do diagnóstico são essenciais para que a estrutura volte a atender aos requisitos básicos de durabilidade e segurança. 


\section{PROCEDIMENTOS METODOLÓGICOS}

\subsection{Vistoria}

Seguindo o método proposto por Linchtenstein (1986) para levantamento das informações, o processo iniciou por uma vistoria no Compartimento 1 da subestação para avaliação da gravidade dos danos e definição das condutas mais adequadas e suficientes para elaboração do diagnóstico.

No local foi verificada a presença de fuligem cobrindo a maior parte dos elementos estruturais, e ainda o desplacamento quase generalizado do reboco do teto, deixando expostos blocos cerâmicos e vigotas (Figura 3 (b)).

(a)

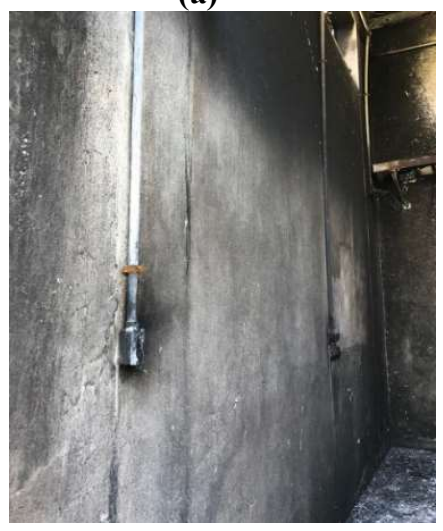

(b)

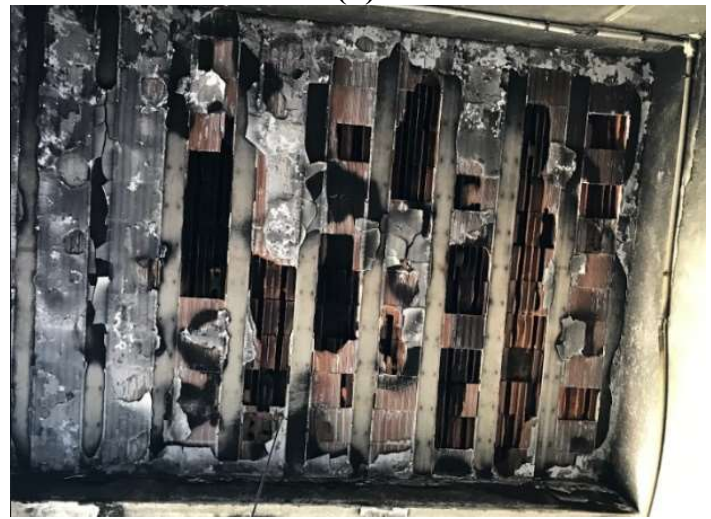

Figura 3: Compartimento 1 - parede coberta por fuligem (a) e desplacamento de reboco do teto (b).

Fonte: Autores (2019).

Nas interfaces entre estrutura e reboco, houve perda de aderência com consequente quebra do reboco (Figura 4 (a)). Já na interface estrutura-alvenaria, foi possível visualizar fissuras por movimentação térmica, às quais margeavam toda a interface.

A alvenaria, por sua vez, apresentou trincas verticais em alguns pontos, o que indica que houve dilatação térmica nesse material. Além das trincas verticais, era visível a existência de mapeamento de fissuras no reboco das parede, como pode ser observado na Figura 4(b), sugerindo que houve contração do reboco devido ao efeito da calcinação.

(a)

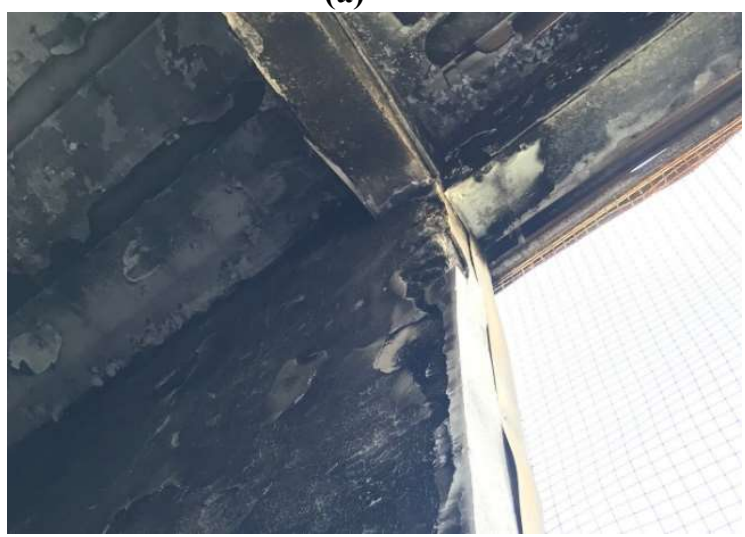

(b)

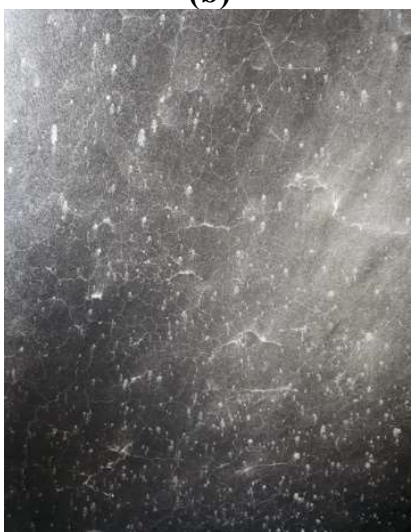

Figura 4: Compartimento 1 - Desplacamento do reboco junto ao pilar (a) e mapeamento de fissuras no reboco (b). Fonte: Autores (2019).

Durante a vistoria realizada no Compartimento 2 e na sala de quadros da subestação também foi constatada a existência de fissuras na interface estrutura-alvenaria e trincas verticais nas paredes, como observado na Figura 5. Em alguns casos foi possível notar, ainda, fissuras em forma de escamas, as quais configuram trincas de cisalhamento originadas pelo esforço entre os dois materiais. 
(a)

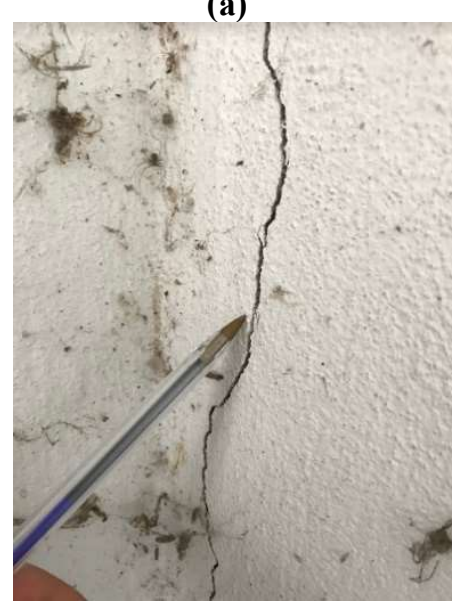

(b)

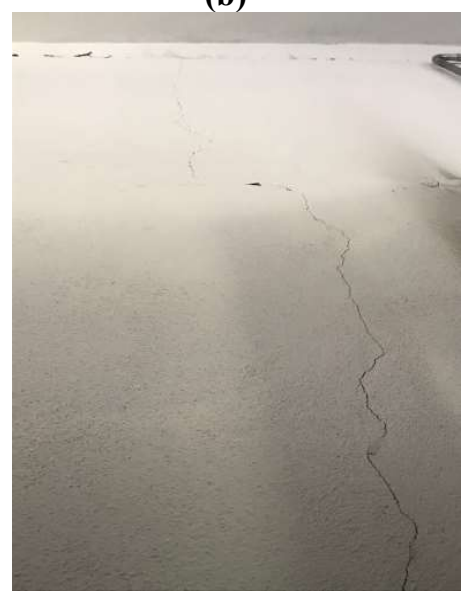

Figura 5: Trinca na interface pilar-alvenaria no compartimento 2 (a) e trinca vertical na alvenaria na sala de quadros (b). Fonte: Autores (2019).

\subsection{Ensaios}

Após vistoria do local para deteç̧ão das manifestações patológicas existentes, foram realizados ensaios normatizados nos elementos estruturais do Compartimento 1, a fim de avaliar as condições da estrutura atingida pelo incêndio. A Tabela 1 relaciona os ensaios realizados, com os objetivo, norma técnica vigente e elemento ensaiado.

Tabela 1 - Lista dos ensaios realizados com os objetivos e respectivas normas.

\begin{tabular}{c|c|c|c}
\hline Ensaio & Objetivo & Norma & $\begin{array}{c}\text { Elementos } \\
\text { ensaiados }\end{array}$ \\
\hline Esclerometria & $\begin{array}{c}\text { Com base no índice esclerométrico, encontra-se a dureza } \\
\text { superficial do elemento estrutural, para em seguida se } \\
\text { estimar a resistência à compressão }\end{array}$ & $\begin{array}{c}\text { NBR 7584 } \\
\text { (ABNT, 2012) }\end{array}$ & $\begin{array}{c}\text { Pilares P13 } \\
\text { e P9 e viga } \\
\text { V6 }\end{array}$ \\
\hline Ultrassom & $\begin{array}{c}\text { Com a velocidade de propagação obtida, determinar o } \\
\text { módulo elástico dinâmico, o módulo elástico estático e, por } \\
\text { fim, a resistência à compressão }\end{array}$ & $\begin{array}{c}\text { NBR 8802 } \\
\text { (ABNT, 2019) }\end{array}$ & $\begin{array}{c}\text { Pilares P13 } \\
\text { e P9 }\end{array}$ \\
\hline $\begin{array}{c}\text { Método } \\
\text { colorimétrico } \\
\text { por fenolftaleína }\end{array}$ & $\begin{array}{c}\text { Identificar a frente de carbonatação por meio da mudança } \\
\text { de coloração causa pela fenolftaleína ao entrar em contato } \\
\text { com um corpo de pH alcalino }\end{array}$ & - & Pilar P13 \\
\hline $\begin{array}{c}\text { Potencial de } \\
\text { corrosão }\end{array}$ & $\begin{array}{c}\text { Obtenção do potencial de corrosão em armaduras inseridas } \\
\text { na estrutura de concreto armado }\end{array}$ & $\begin{array}{c}\text { C876 } \\
\text { (ASTM, 2015) }\end{array}$ & Pilar P13 \\
\hline $\begin{array}{c}\text { Extração de } \\
\text { testemunho }\end{array}$ & $\begin{array}{c}\text { Extrair parte do elemento estrutural para avaliação precisa } \\
\text { das condições da estrutura por meio de ensaios }\end{array}$ & $\begin{array}{c}\text { NBR 7680 } \\
\text { (ABNT, 2015) }\end{array}$ & Pilar P13 \\
\hline $\begin{array}{c}\text { Resistência à } \\
\text { compressão }\end{array}$ & $\begin{array}{c}\text { Obtenção da resistência à compressão do elemento } \\
\text { estrutural rompido em prensa hidráulica }\end{array}$ & $\begin{array}{c}\text { NBR 5739 } \\
\text { (ABNT, 2018) }\end{array}$ & Pilar P13 \\
\hline
\end{tabular}

Fonte: Autores (2019).

\subsubsection{Observações importantes sobre os ensaios realizados:}

- $\quad$ No ensaio de esclerometria, o esclerômetro foi utilizado na posição horizontal e seu resultado, após desconsiderar os índices esclerométricos (IE) que divergiam mais de $10 \%$ da média, foi lançado no ábaco de correlação de resistência à compressão e IE do próprio aparelho, estimando-se assim a resistência à compressão do elemento.

- No ensaio de ultrassom optou-se pelo método indireto para obtenção dos resultados devido às condições do ambiente. A cada altura escolhida para a execução do ensaio, posicionou-se os transdutores a distâncias de $15 \mathrm{~cm}$ e 30 $\mathrm{cm}$, com auxílio de linhas de referência, totalizando duas medições para cada altura. 


\section{RESULTADOS E DISCUSSÕES}

Os resultados seguintes se referem aos pilares P13 e P9 e viga V6 do Compartimento 1, indicados na Figura 6.

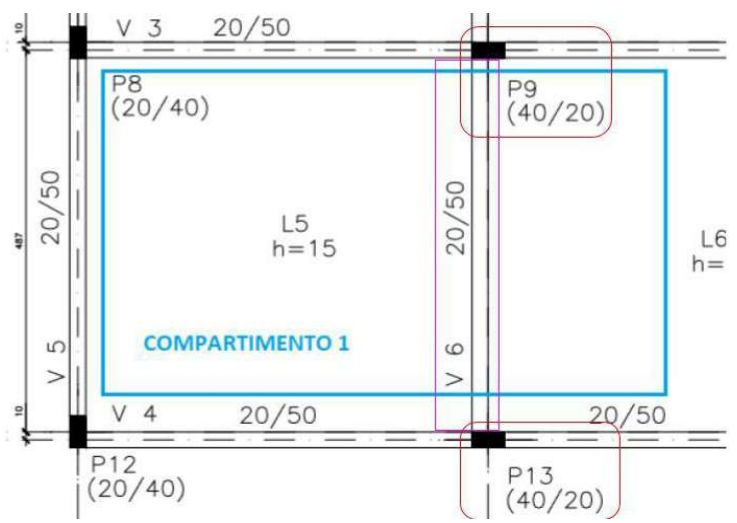

Figura 6: Parte da planta estrutural de cobertura com identificação dos elementos ensaiados.

Fonte: Projeto estrutural da cobertura (2007).

\subsection{Pilar P13}

Seguindo os procedimentos descritos nas normas correspondentes, foram executados, nesse pilar, os ensaios de esclerometria, ultrassom e potencial de corrosão. Além disso, foi feita uma extração de testemunho, o qual foi submetido ao ensaio colorimétrico e ao ensaio de compressão axial.

\subsubsection{Esclerometria}

Seguindo as prescrições da NBR 7584 (ABNT, 2012), foram aferidos 16 índices esclerométricos, que juntos compuseram, salvo alguns descartes devido à discrepâncias numéricas, o índice esclerométrico médio do pilar P13 correspondente a 41,4. Em posse do valor de IE e sabendo que o ensaio foi executado na posição a $0^{\circ}$, determinou-se a resistência à compressão correspondente à sua dureza superficial pelo ábaco do aparelho, sendo aproximadamente igual a $43 \mathrm{MPa}$.

Levando-se em consideração que a resistência característica à compressão estimada em projeto estrutural era equivalente a $25 \mathrm{MPa}$, o valor obtido no ensaio simula um ótimo resultado, apresentando quase o dobro do fck. Entretanto, a esclerometria, por si só, não é conclusiva.

Um dos fatores que influenciam o resultado de dureza superficial é a carbonatação. Logo, o resultado pode significar um ganho de resistência do elemento estrutural pela qualidade do concreto e de seu lançamento ou que, durante a ocorrência do incêndio houve a calcinação do concreto devido ao calor liberado. Neste caso, o hidróxido de cálcio - $\mathrm{Ca}(\mathrm{OH}) 2$ se dissociou e preencheu os poros vazios do concreto, conferindo ao material uma maior dureza superficial temporária e, consequentemente, uma maior resistência à compressão, também temporária, pois o sal presente nos poros é solúvel em água.

Vale ressaltar que até a fumaça pode ter contribuído para uma alteração do resultado, visto que ela contém $\mathrm{CO}_{2}$ que ao entrar em contato com o $\mathrm{Ca}(\mathrm{OH}) 2$, forma carbonato de cálcio - $\mathrm{CaCO}_{3}$ - desencadeando as mesmas consequências que a calcinação.

\subsubsection{Ultrassom}

Devido a limitação de acesso, no pilar P13 o ensaio foi executado pelo método indireto, com posicionamento dos transdutores em paralelo, na mesma face da estrutura.

Em posse das velocidades do onda ultrassônica fornecidas pelo aparelho de ultrassom, estimou-se o módulo de elasticidade dinâmico do concreto (Ed) conforme a C597 (ASTM, 2016), por meio da equação (1):

$$
\mathrm{Ed}=\mathrm{v}^{2} \rho(1+\mu)(1-2 \mu) /(1-\mu)
$$


Onde,

Ed - Módulo de elasticidade dinâmico, expresso em MPa;

$\rho$ - Massa específica, expressa em $\mathrm{kg} / \mathrm{m}^{3}$;

$\mathrm{v}$ - Velocidade de propagação da onda ultrassônica, expressa em $\mathrm{km} / \mathrm{s}$;

$\mu$ - Coeficiente de Poisson.

Por fim, foi determinado a resistência à compressão pela equação (2) proposta por Cánovas (1988):

$$
\mathrm{fc}=3,5 \cdot 10^{-9} \cdot \mathrm{Ed}^{2}-10^{-3} \cdot \mathrm{Ed}+200
$$

Onde,

Ed - Módulo de elasticidade dinâmico, expresso em $\mathrm{kgf} / \mathrm{cm}^{2}$;

$\mathrm{Fc}$ - Resistência à compressão do concreto, expresso em kgf/ $\mathrm{cm}^{2}$.

Considerando a massa específica do concreto igual a $2200 \mathrm{~kg} / \mathrm{m}^{3}$, obteve-se os resultados discretizados na Tabela 2 .

Tabela 2 - Resultados obtidos no ensaio de ultrassom feito no pilar P13.

\begin{tabular}{c|c|c}
\hline Velocidade (m/s) & Ed (MPa) & fc (MPa) \\
\hline 2055 & 8361,6 & 14,1 \\
\hline \multicolumn{2}{r}{ Fonte: Autores (2019). }
\end{tabular}

Diante do resultado abaixo do fck de projeto, constatou-se uma redução da resistência à compressão do concreto após o sinistro de incêndio. Situação que pode estar atribuída a alterações na micro e macroestrutura do concreto devido à ação de altas temperaturas. De todo modo, esse resultado deve ser respaldado por ensaios complementares, uma vez que foi obtido por correlação.

\subsubsection{Método Colorimétrico}

No testemunho extraído inicialmente verificou-se o posicionamento da armadura, observando um cobrimento de $3,00 \mathrm{~cm}$ e 3,50 cm, para as faces interna e externa, respectivamente. Em seguida, borrifou-se a fenolftaleína por toda a superfície do testemunho, o que permitiu detectação da camada carbonatada, conforme mostrado na Figura 7.

(a)

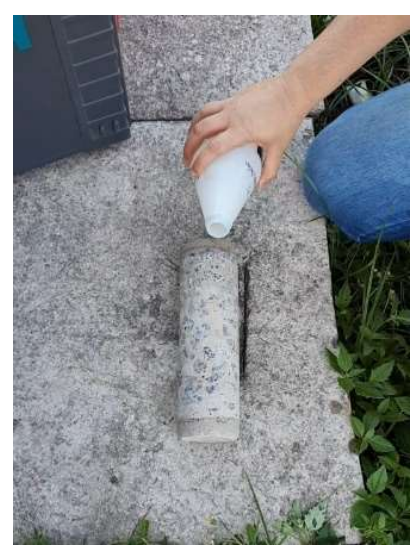

(b)

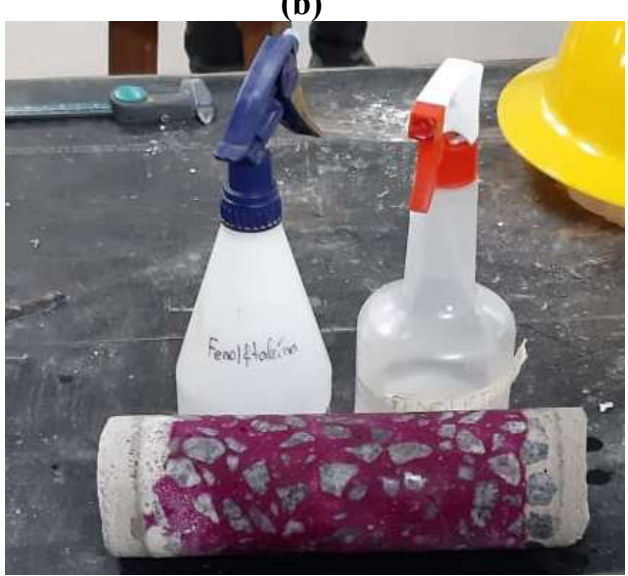

Figura 7: Aplicação da fenolftaleína no testemunho (a) e a coloração resultante (b).

Fonte: Autores (2019).

Por meio de um paquímetro digital foram feitas 11 leituras de frentes de carbonatação (espessura da camada incolor) com o intuito de obter um valor médio representativo. Assim, a frente de carbonatação média foi de 1,487 na face interna do pilar e de 1,433 em sua face externa. A face interna corresponde àquela voltada para o interior da subestação, enquanto a face externa faz referência ao exterior da edificação. Vale destacar que na aferição das medidas foi descontada a espessura do revestimento argamassado. 
Considerando os cobrimentos aferidos, bem como os valores médios de carbonatação obtidos, conclui-se que no momento do ensaio a armadura ainda estava protegida. Contudo, tal condição não pode ser assegurada a longo prazo, pelo avanço da carbonatação da superfície para o interior do material. Quando a frente de carbonatação atinge a armadura, a película apassivadora, que usualmente reveste e protege a superfície da armadura de aço contra a corrosão, torna-se instável e é quebrada, permitindo o desenvolvimento das interações destrutivas entre o aço e o ambiente.

\subsubsection{Extração de testemunho}

Após regularização das bases em uma retífica, o testemunho foi submetido a esforço de compressão 72 horas após a extração, e se rompeu na forma cônica bipartida. Na extração usou-se uma máquina de classe 2 e marca A. J Amsler, que possui serra copo rotativa e é refrigerada a água. A Tabela 3 indica os resultados contidos no relatório fornecido pelo laboratório onde ocorreu o ensaio.

Tabela 3 - Resultados do ensaio de extração de testemunho no pilar P13.

\begin{tabular}{|c|c|c|c|c|c|c|c|}
\hline $\begin{array}{l}\mathbf{N}^{0} \\
\mathbf{C P}\end{array}$ & $\begin{array}{l}\text { Idade } \\
\text { (dias) }\end{array}$ & $\begin{array}{c}\text { Diâmetro } \\
\text { d (cm) }\end{array}$ & $\begin{array}{l}\text { Altura } \\
\text { h (cm) }\end{array}$ & $\begin{array}{c}\text { Massa Esp. } \\
\text { Aparente } \\
\left(\mathbf{k g} / \mathbf{m}^{3}\right)\end{array}$ & $\begin{array}{c}\text { Resistência à } \\
\text { Compressão } \\
\boldsymbol{f}_{\text {cj,ext,inicial }} \text { (MPa) }\end{array}$ & $\begin{array}{l}\text { Resistência à } \\
\text { Compressão* } \\
f_{c j, e x t}(\mathrm{MPa})\end{array}$ & $\begin{array}{l}\text { Tipo de } \\
\text { Ruptura }\end{array}$ \\
\hline 1 & $>360$ & 7,39 & 15,3 & 2316 & 18,1 & 19,9 & B \\
\hline
\end{tabular}

(*) Correlação relativa à relação $\mathrm{h} / \mathrm{d}$, coeficientes $\left(\mathrm{k}_{1}\right.$ e $\left.\mathrm{k}_{\mathrm{i}}\right)$.

Fonte: Laboratório de Ensaios em Materiais de Construção da UFES (2019).

Conforme recomendação da NBR 7680 (ABNT, 2015), os testemunhos devem ser ensaiados no sentido do lançamento do concreto. Como no caso o elemento ensaiado era um pilar, a extração foi feita na direção ortogonal ao lançamento, sendo portanto, necessário correção do resultado, devido à orientação da rede capilar ser diferente no testemunho. Ainda segundo a norma supracitada, os resultados obtidos no rompimento dos testemunhos devem ser identificados por fci,ext,inicial, e após correção, informados como fci,ext.

Deste modo, diante das dimensões medidas iguais a 7,39 cm de diâmetro (d) e 15,30 cm de altura (h), como a relação h/d foi ligeiramente superior a dois, foram feitas correções pelo coeficiente k1 consultado na Norma, e também pelo efeito da umidade do testemunho $(\mathrm{k} 4)$. Obtendo assim, resistência à compressão (fci,ext) igual a 19,9 MPa, valor inferior a resistência característica à compressão indicada no projeto $($ fck $=25 \mathrm{MPa})$.

A resistência obtida pelo ensaio, juntamente com o resultado de resistência encontrado no ensaio de ultrassom, evidenciam a redução da capacidade portante da estrutura, o que caracteriza perda de segurança estrutural no pilar ensaiado.

A diferença numérica entre os valores de resistência obtidos pelos dois ensaios pode ser explicada por uma provável heterogeneidade no elemento estrutural, tendo em vista que o testemunho foi extraído em uma seção transversal diferente da que se executou o ensaio de ultrassom. Todavia, o ensaio de compressão axial realizado no testemunho produz resultados mais confiáveis, uma vez que a resistência é obtida de forma direta.

\subsubsection{Potencial de corrosão}

O eletrodo de referência utilizado no ensaio de potencial de corrosão foi o cobre/sulfato de cobre $(\mathrm{Cu} / \mathrm{CuSO} 4)$. Nesse caso, a norma C-876 (ASTM, 2015) apresenta as probabilidades de ocorrência de corrosão como mostrado na Tabela 4.

Tabela 4 - Probabilidade de ocorrência de corrosão em função da diferença de potencial.

\begin{tabular}{c|c}
\hline Diferença de potencial $(\Delta \mathbf{V})$ & Probabilidade de corrosão \\
\hline$\Delta \mathrm{V}>-0,20$ & Probabilidade de inocorrência de corrosão do aço é maior que $90 \%$ \\
\hline$-0,2<\Delta \mathrm{V}<-0,35$ & Atividade de corrosão no aço é incerta \\
\hline$\Delta \mathrm{V}>-0,35$ & Probabilidade de ocorrência de corrosão do aço é maior que $90 \%$ \\
\hline
\end{tabular}

Fonte: Adaptado de C-876 (ASTM, 2015). 
Como a armadura não estava exposta foi necessário fazer a remoção do revestimento argamassado e cobrimento de concreto para ter acesso à mesma. Em seguida, realizou-se o procedimento seguindo as diretrizes da norma supracitada, obtendo, por meio da aferição do multímetro, uma diferença de potencial de $-233 \mathrm{mV}$.

Portanto, de acordo com a Tabela 4, a atividade de corrosão do aço no ponto estudado é incerta, logo, o resultado do ensaio é inconclusivo.

\subsection{Pilar P9}

\subsubsection{Esclerometria}

Após 16 medições com o esclerômetro posicionado na posição horizontal, foi obtido o Índice Esclerométrico Médio de 41,9, valor que pelo ábaco corresponde a resistência à compressão igual a $43 \mathrm{MPa}$. Assim como no pilar P13, o resultado encontrado não é conclusivo, sendo necessário a realização de outros ensaios para corroboração do resultado obtido.

\subsubsection{Ultrassom}

Da mesma forma que para o pilar P13, foram feitas algumas leituras de velocidade no pilar P9, também por meio do método indireto. Os resultados estão mostrados na Tabela 5.

Tabela 5 - Resultados obtidos no ensaio de ultrassom feito no pilar P9.

\begin{tabular}{c|c|c}
\hline Velocidade (m/s) & Ed (MPa) & fc (MPa) \\
\hline 2582 & 13200,1 & 12,9 \\
\hline \multicolumn{2}{r}{ Fonte: Autores (2019). }
\end{tabular}

Fonte: Autores (2019).

Segundo Whitehurst (1951), para velocidades de propagação da onda entre 2000 e $3000 \mathrm{~m} / \mathrm{s}$ indica que a qualidade interna do concreto é ruim, o que corrobora o baixo resultado de resistência à compressão.

\subsection{Viga V6}

\subsubsection{Esclerometria}

Para a viga V6, diferentemente dos pilares, o esclerômetro foi posicionado verticalmente, de baixo para cima para execução de duas malhas. Na malha 1 foi obtido um Índice Esclerométrico Médio de 40,1, já na malha 2, IE equivalente a 42, valores que correspondem a resistências à compressão iguais a $33 \mathrm{MPa}$, e $37 \mathrm{MPa}$, respectivamente.

Essa variação pode ser explicada pela heterogeneidade do concreto, visto que a estrutura foi exposta à altas temperaturas, e também devido a influência das condições da superfície a no resultado do ensaio.

Com esses valores, é possível inferir que a resistência obtida foi superestimada por apresentar resultados superiores ao fck de projeto (25 MPa). Entretanto, assim como para os pilares, o resultado da esclerometria não é conclusivo, e deve ser analisado juntamente com ensaios complementares.

\subsubsection{Ultrassom}

No elemento estrutural V6, o ensaio de propagação de onda ultrassônica foi feito de forma direta, com um transdutor em uma face do elemento estrutural e o outro na face oposta à primeira. Os resultados obtidos constam na Tabela 6.

Tabela 6 - Resultados obtidos no ensaio de ultrassom feito na viga V6.

\begin{tabular}{c|c|c}
\hline Velocidade (m/s) & Ed (MPa) & fc (MPa) \\
\hline 2760 & 15082,85 & 12,9 \\
\hline \multicolumn{2}{r}{ Fonte: Autores (2019). }
\end{tabular}




\section{CONCLUSÃO}

A partir dos resultados do ensaio esclerométrico verificou-se uma alta resistência à compressão em todos elementos os estruturais avaliados, apresentando valores que superam até o estimado em projeto. Os resultados superestimados podem ser explicados devido ao processo de calcinação do concreto ocorrido em função das altas temperaturas. $\mathrm{O}$ fenômeno desencadeou carbonatação nas estruturas, liberando assim, moléculas de carbonato de cálcio as quais preencheram os poros das faces mais externas.

Pelo ensaio colorimétrico, constatou-se uma frente de carbonatação de aproximadamente $1,5 \mathrm{~cm}$. Como o cobrimento da armadura era cerca de $3 \mathrm{~cm}$, conclui-se que no momento do ensaio, a armadura estava protegida. Contudo, tal condição não pode ser assegurada a longo prazo, pelo avanço gradual da frente de carbonatação da superfície para o interior do material.

Além disso, embora pela norma o valor obtido no potencial de corrosão se enquadre na faixa cujo resultado é inconclusivo, esse resultado ficou muito próximo do limite no qual a armadura tem baixa probabilidade de desenvolver corrosão.

Por fim, no pilar P13, o ensaio de rompimento sob esforço de compressão no testemunho apontou uma perda de cerca de $20 \%$ da resistência projetada, e o ensaio de propagação de onda ultrassônica indicou, uma baixa qualidade do concreto.

Devido a esse elemento estrutural ter sido um dos mais afetados pelo sinistro, o resultado foi replicado para as demais estruturas adjacentes ao Compartimento 1, portanto, conclui-se que a estrutura da subestação sofreu alterações na sua microestrutura, afetando assim, a integridade estrutural da mesma.

\section{REFERÊNCIAS}

AMERICAN SOCIETY FOR TESTING AND MATERIALS. ASTM C-876: Standard Test Method for Corrosion Potentials of Uncoated Reinforcing Steel in Concrete. West Conshohocken, 2015.

AMERICAN SOCIETY FOR TESTING AND MATERIALS. ASTM C-597: Standard Test Method for Pulse Velocity Through Concrete. West Conshohocken, 2016

ASOCIACIÓN LATINOAMERICANA DE CONTROL DE CALIDAD, PATOLOGÍA Y RECUPERACIÓN DE LA CONSTRUCCIÓN - ALCONPAT. Boletín Técnico: Inspección, Diagnóstico y Prognóstico en la Construcción Civil. México, 2013.

ASSOCIAÇÃO BRASILEIRA DE NORMAS TÉCNICAS. NBR 5739: Concreto - Ensaio de compressão de corpos de prova cilíndricos. Rio de Janeiro, 2018.

ASSOCIAÇÃO BRASILEIRA DE NORMAS TÉCNICAS. NBR 6118: Projeto de estruturas de concreto Procedimento. Rio de Janeiro, 2004

ASSOCIAÇÃO BRASILEIRA DE NORMAS TÉCNICAS. NBR 7584: Concreto endurecido - Avaliação da dureza superficial pelo esclerômetro de reflexão - Método de ensaio. Rio de Janeiro, 2012

ASSOCIAÇÃO BRASILEIRA DE NORMAS TÉCNICAS. NBR 7680: Concreto - Extração, preparo, ensaio e análise de testemunhos de estruturas de concreto - Parte 1: Resistência à compressão. Rio de Janeiro, 2015.

ASSOCIAÇÃO BRASILEIRA DE NORMAS TÉCNICAS. NBR 8802: Concreto endurecido - Determinação da velocidade de propagação de onda ultrassônica. Rio de Janeiro, 2019.

ASSOCIAÇÃO BRASILEIRA DE NORMAS TÉCNICAS. NBR 13752: Perícias de engenharia na construção civil. Rio de Janeiro, 1996.

ASSOCIAÇÃO BRASILEIRA DE NORMAS TÉCNICAS. NBR 15200: Projeto de estruturas de concreto em situação de incêndio. Rio de Janeiro, 2012. 
BRITISH STANDARD ASSOCIATION. BS 1881 Part 203: Recommendations for measurement of velocity of ultrasonic pulses in concrete. 1986.

CANOVAS, M. F. Patologia e terapia do concreto armado. São Paulo: PINI, 1988.

CENTRO BRASILEIRO DE CONSTRUÇÃO EM AÇO (CBCA). A Evolução da Construção em Aço no Brasil. 2015. Disponível em www.cbca-acobrasil.org.br/site/noticias-detalhes.php?cod=7074. Acesso em: 06 jul. 2019.

COSTA, C. N.; SILVA, V. P. Estruturas de concreto em situação de incêndio. Brasília, 2002.

G1 GLOBO. Incêndio atinge subestação de energia, em Vitória. 2019. Disponível em: https://g1.globo.com/es/espirito-santo/noticia/2019/05/03/incendio-atinge-subestacao-de-energia-na-ufes-emvitoria.ghtml. Acesso em: 06 de julho, 2019.

LICHTENSTEIN, Norberto. Boletim Técnico: Patologia das Construções. EPUSP n, 1986.

NEPOMUCENO. M.C. S. Ensaios não destrutivos em betão. Tese: Livre docência - Universidade da Beira Interior. Covilha, Portugal, 1999.

NEVILlE, A. M. Propriedades do Concreto. $3^{\text {a }}$ ed. São Paulo, 2015.

WHITEHURST, E. A. Soniscope tests concrete structures. Concrete Institute Proc. 1951. 